\title{
Comparison of dynamic properties of InP/ InAs quantum-dot and quantum-dash lasers
}

Cite as: Appl. Phys. Lett. 109, 161104 (2016); https://doi.org/10.1063/1.4965846

Submitted: 21 July 2016 . Accepted: 08 October 2016 . Published Online: 20 October 2016

T. Sadeev, D. Arsenijević (D), and D. Bimberg
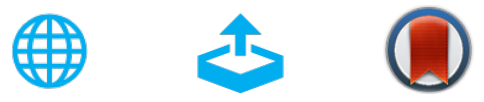

View Online

\section{ARTICLES YOU MAY BE INTERESTED IN}

Perspective: The future of quantum dot photonic integrated circuits

APL Photonics 3, 030901 (2018); https://doi.org/10.1063/1.5021345

$1.3 \mu \mathrm{m}$ room-temperature GaAs-based quantum-dot laser

Applied Physics Letters 73, 2564 (1998); https://doi.org/10.1063/1.122534

High efficiency low threshold current $1.3 \mu \mathrm{m}$ InAs quantum dot lasers on on-axis (001) GaP/Si Applied Physics Letters 111, 122107 (2017); https://doi.org/10.1063/1.4993226

\section{Lock-in Amplifiers up to $600 \mathrm{MHz}$}
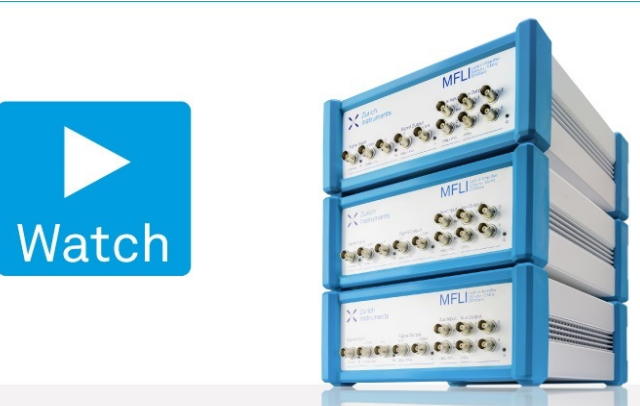


\title{
Comparison of dynamic properties of InP/InAs quantum-dot and quantum-dash lasers
}

\author{
T. Sadeev, ${ }^{1, a)}$ D. Arsenijević, ${ }^{1}$ and D. Bimberg ${ }^{1,2}$ \\ ${ }^{1}$ Institut für Festkörperphysik, Technische Universität Berlin, Berlin 10623, Germany \\ ${ }^{2}$ King Abdulaziz University, 22254 Jeddah, Saudi Arabia
}

(Received 21 July 2016; accepted 8 October 2016; published online 20 October 2016)

\begin{abstract}
The dynamic properties of MOVPE grown InP/InAs quantum-dot and quantum-dash lasers, showing identical structural design, emitting in the C-band are investigated and compared to each other. Based on the small-signal measurements, we show the impact of the density of states function on the cut-off frequency, being larger for quantum dots at low currents, and reaching similar values for quantum dashes only at higher currents. The large-signal measurements show error-free data transmission at 22.5 and $17.5 \mathrm{Gbit} / \mathrm{s}$ for the quantum-dot and quantum-dash lasers. Published by AIP Publishing.

[http://dx.doi.org/10.1063/1.4965846]
\end{abstract}

Semiconductor lasers are the key components for optical communication systems. Significant improvements of their performance, like lower threshold current density or larger $\mathrm{T}_{0}$, have been achieved in the last decades, thanks to implementing zero-dimensional structures-quantum dots (QDots) in active GaAs- and InP-based layers. ${ }^{1,2}$ The present QDot GaAs-based devices benefit from the large local carrier confinement and record material gain, ${ }^{3-5}$ resulting from the deltafunction like density of states (DOS), low chirp and threshold current density, making them very attractive for direct modulation. ${ }^{1}$ Most of the initial brake-troughs were demonstrated for GaAs-based devices, finding the applications in the O-band for local area networks.

The work on InP-based nanodevices started much later and is much less detailed, although presently in long distance and medium range communication systems InP-lasers are deployed. Many InP material science groups initially did not obtain true QD gain regions like in GaAs, but so-called Q-Dashes, a kind of broken QWires, ${ }^{6,7}$ show a completely different density of states function. It is not really clear until now how the laser properties, in particular, the dynamic ones, between dash-based and dot-based differ. A number of theoretical publications compared the modulation dynamics of QDot and QDash lasers ${ }^{8-10}$ and found differences; so far, no experimental results however have been presented in order to support these investigations. Most of the results published on QDash-lasers are based on MBE growth, ${ }^{11-13}$ whereas much fewer QDot laser results ${ }^{14-16}$ are based on MOVPE growth.

It is the purpose of this paper to compare the dynamic properties (small- and large-signal modulation) of MOVPE grown QDash and QD lasers emitting around $1.55 \mu \mathrm{m}$, which are identical as heterostructures and as processed devices, except some details, which were varied during the growth of the active area, leading to either dots or dashes. An approach to develop fast and energy efficient laser sources for C-band optical communication can be based on our results here. Previously, only the gain of both the types of nanostructures had been compared for such identical boundary conditions. ${ }^{16}$

\footnotetext{
${ }^{\text {a) }}$ Author to whom correspondence should be addressed. Electronic mail: tagir@mailbox.tu-berlin.de
}

The direct intensity modulation of semiconductor lasers is used in the simplest form as on/off keying (OOK), which is a cost-effective solution for medium range data rate communication, e.g., for $100 \mathrm{GbE} 4 \times 25 \mathrm{G}$, OTU4 4x28G and SONET networks. The carrier dynamics of the lasers is influenced by the ratio between the number of states in the carrier reservoir and the QDot/Dash ensemble. This ratio determines capture rate, which was observed for GaAs QD-lasers to be ultrafast ${ }^{17}$ and state filling factor, ${ }^{10}$ thus affecting the differential gain, which defines the D-factor and eventually the modulation bandwidth. The modulation bandwidth is the result of an interplay between the differential gain and gain compression. Therefore, an increase in the differential gain does not necessarily lead to larger modulation bandwidths. ${ }^{18}$ The recently reported state-of-the-art MBE grown InP/InAs QDot lasers ${ }^{19}$ demonstrate $-3-\mathrm{dB}$ modulation bandwidth of $15 \mathrm{GHz}$ and open eye-diagrams up to $25 \mathrm{~Gb} / \mathrm{s}$; however, no reports on the PRBS length used and bit-error-rate measurement results have been provided yet. QDash lasers demonstrate $\sim 10 \mathrm{GHz}$ and $10 \mathrm{~GB} / \mathrm{s}$ of $-3-\mathrm{dB}$ bandwidth and error-free transmission bit rate, respectively. ${ }^{20}$ No publications till this date are known to authors regarding small- and large-signal experiments with MOVPE grown InP/InAs QDot and QDash lasers. Reports on small-signal modulation bandwidth achieved with QDot/QDash lasers based on other material systems can be found in Ref. 21.

The short cavity laser structures (QDot: $440 \mu \mathrm{m}$; QDash: $420 \mu \mathrm{m}$, ridge width is $1.4 \mu \mathrm{m}$, as cleaved facets) investigated in this work are grown by MOVPE on n-type (001) InP substrates. For the formation of QDashes, a higher trimethylindium flow is used. Their active region consists of 7 stacked layers in an $\mathrm{In}_{0.78} \mathrm{Ga}_{0.22} \mathrm{As}_{0.47} \mathrm{P}_{0.53}$ matrix, enclosed by an $\mathrm{In}_{0.82} \mathrm{Ga}_{0.18} \mathrm{As}_{0.40} \mathrm{P}_{0.60}$ waveguide. The laterally singlemode buried heterostructures are formed by deep etching through the active region and regrowth of $\mathrm{p} / \mathrm{n}$-blocking and contact layers. Further details of the material growth, processing and results of material characterisation are reported in Ref. 22. Since the QDot and QDash lasers have the same structure except the nanostructure type, consistent comparison of their dynamics is eased. The static characteristics, the LIV curve and the optical spectra at $10 \times \mathrm{I}_{\mathrm{thr}}$, are shown in 

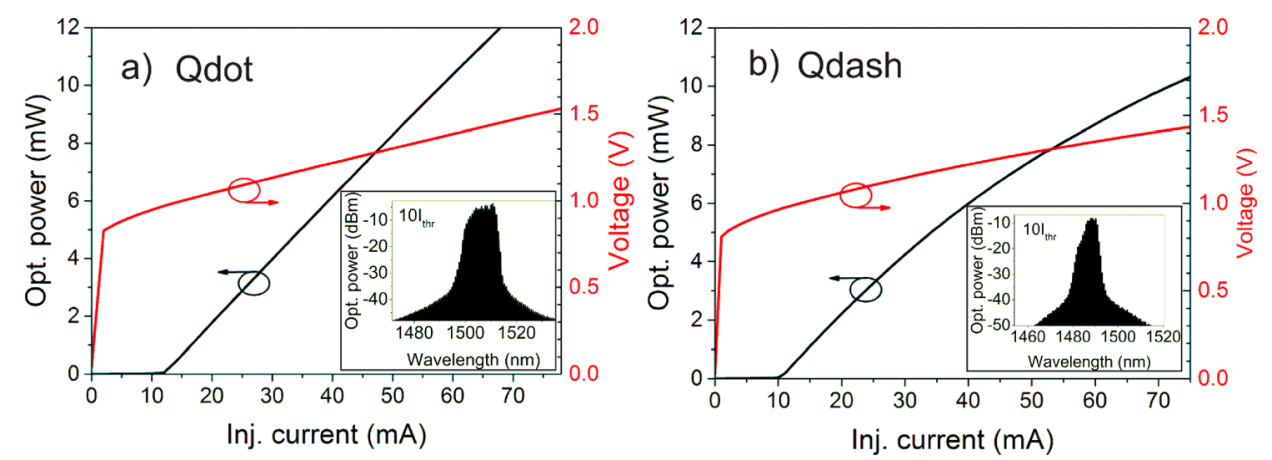

FIG. 1. LIV curve and optical spectrum (inset) of QDot (a) and QDash (b) laser.
Figs. 1(a) and 1(b) for QDot and QDash lasers, respectively, which were mounted identically on heat sinks.

The threshold currents of $12 \mathrm{~mA}$ and $11 \mathrm{~mA}$ for QDot and QDash lasers differ slightly from each other, whereas the differential quantum efficiency and the series resistance are $26 \%$ and $\sim 9 \Omega$ for both the devices. The optical spectra at $10 \times \mathrm{I}_{\text {thr }}$ are inhomogeneously broadened as demonstrated in the insets of Figs. 1(a) and 1(b). QDash lasers show a bending of the L-I curve that might limit the maximum -3$\mathrm{dB}$ bandwidth. The bias dependent small-signal modulation responses of QDot and QDash lasers performed on a calibrated setup similar to one used in Ref. 23 are shown in Figs. 2(a) and 2(b).

Increased damping and relaxation oscillation (RO) resonance shift are observed at larger bias currents for QDot and QDash lasers. A damping of RO can result from several nonlinear processes: spectral hole burning, hot carrier effects, cavity standing wave effects and coupling of spontaneous emission into the lasing mode. ${ }^{24}$ The damping of the RO peak is significantly lower for QDash lasers due to the lower gain compression and larger saturation gain, stemming from larger density of the lasing states in QDash gain materials.

A capacitive-like roll-off at low frequencies for QDot lasers has been reported before ${ }^{16}$ and addressed to enhanced non-linear scattering and an injection bottleneck. For QDash lasers, low frequency roll-off is not observed. This may result from the continuous and overlapping DOS of the QDash ensemble, providing stronger coupling. Scarcer filling of QDot states not contributing to lasing results in higher differential gain and consequently in larger resonance frequency at lower bias. ${ }^{10} \mathrm{RO}$ and damping factor $\gamma$ were extracted from Fig. 2 following the method given in Ref. 25. The damping rate vs squared RO-frequency and squared RO-frequency vs current are shown in Figs. 3(a) and 3(b), respectively. The parameters of the linear fit in Fig. 3(a) reveal a K-factor of $0.34 \mathrm{~ns}$ and initial damping $\gamma_{0}=5.4 \mathrm{GHz}$, which leads to a carrier lifetime of $0.18 \mathrm{~ns}$ for QDot lasers and $\mathrm{K}=0.29 \mathrm{~ns}$ and $\gamma_{0}=8.2 \mathrm{GHz}(=0.12 \mathrm{~ns}$ carrier lifetime) for QDash lasers. The lower K-factor for QDash lasers is a result of the lower gain compression discussed above and implies weaker damping of the RO peak, as mentioned before. Carrier lifetime values are comparable with literature, ${ }^{26,27}$ and QDash lasers feature shorter carrier lifetime, probably owing to stronger coupling between the overlapping tails of DOS mentioned above and Auger recombination.

From Fig. 3(b), a lower D-factor for QDash laser is observed, corresponding to a slower increase in the resonance frequency with injected current. Consequently, at low and moderate bias levels (to avoid heating imposed bandwidth limitations), QDash lasers demonstrate smaller RO resonance frequencies and modulation bandwidth in comparison to their QDot counterparts. In the inset of Fig. 3(b), the saturation of -3-dB bandwidth is shown for the QDot and QDash lasers. We observe the -3-dB bandwidth of QDash devices to saturate at higher bias levels in comparison to QDot lasers. Lasers with QDot active material achieve larger values of modulation bandwidth and relaxation frequency at much lower bias currents than similar lasers based on the QDash active media. We explain this by the larger degeneracy of QDash states leading to higher saturation and lower differential gain. ${ }^{10}$ The breakdown of the linear behaviour for QDash lasers at moderately high bias currents in Fig. 3(a) complies with the saturation of the squared RO frequency in Fig. 3(b) and the $-3-\mathrm{dB}$ bandwidth (inset of Fig. 3(b)). This effect might be caused by enhanced carrier escape (i.e., gain compression) from higher energy states of QDashes. The maximum -3-dB bandwidth of our QDot lasers is $8.1 \mathrm{GHz}$, which is $20 \%$ larger than that of our QDash lasers measured at the same bias conditions.
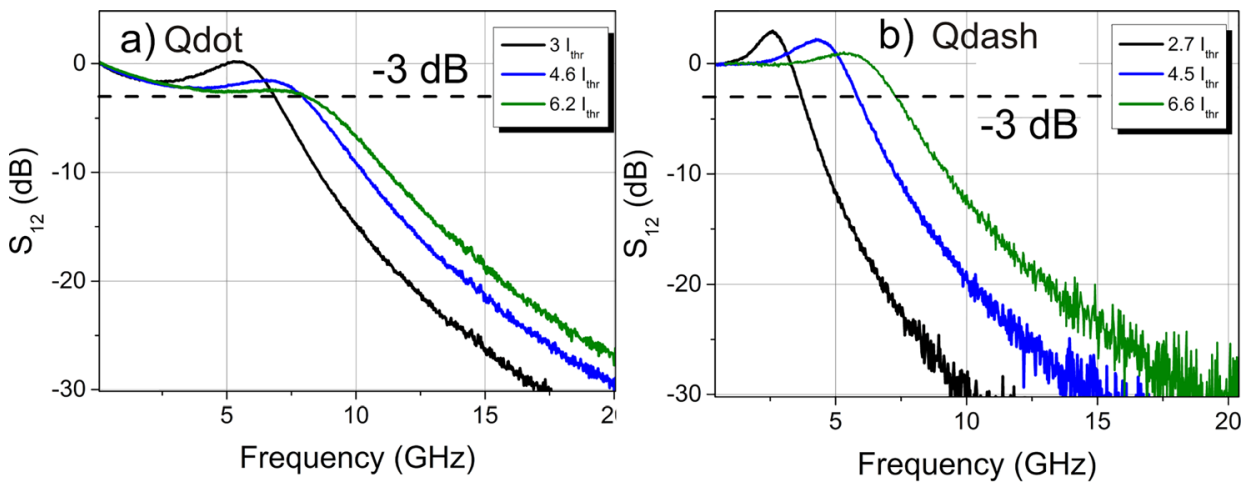

FIG. 2. Small-signal modulation response $\mathrm{S}_{12}$ of QDot (a) and QDash (b) lasers at various bias currents. 


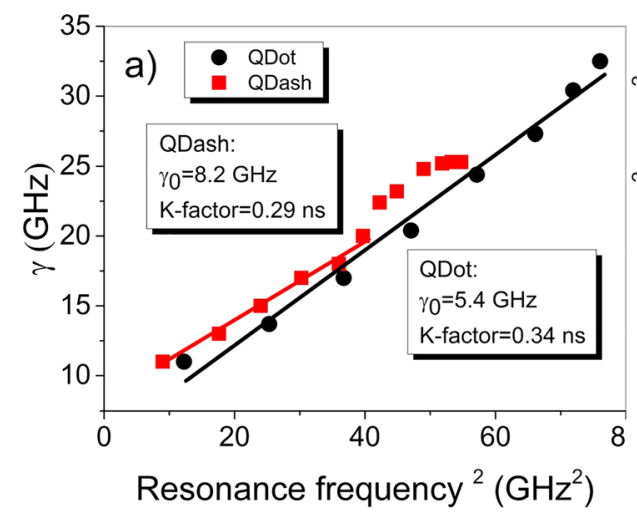

We find this value being comparable to the results reported on the modulation bandwidth of already optimized structures. ${ }^{28}$

Large-signal measurements for both the structures are performed in a back-to-back configuration. Non-return-tozero on-off keying (NRZ OOK) modulation with pseudorandom binary sequence (pattern length of $2^{7}-1$ bits) is used. The bit-error-rate curves are shown in Fig. 4; the eye diagrams, measured with a $50 \mathrm{GHz}$ photodiode and $80 \mathrm{GSa} / \mathrm{s}$ real-time oscilloscope, are shown in the insets of Fig. 4. QDot lasers show an error-free data rate of $22.5 \mathrm{Gbit} / \mathrm{s}$ with a Q-factor of 3.5. For the QDash lasers, the error-free bit rate is $17.5 \mathrm{Gbit} / \mathrm{s}(\mathrm{Q}=4.8)$ with potential up to $20 \mathrm{Gbit} / \mathrm{s}$ with a Q-factor of 3.7.

To summarize, we observe a larger $D$-factor for QDot lasers, which implies a larger resonance frequency at lower bias current, and a saturation of the modulation bandwidth at lower bias levels. This feature can be useful in concepts for energy efficient laser sources. Larger gain compression is the reason for the overdamped RO peak in QDot lasers, whereas moderate damping is observed in QDash devices. Finally, we have demonstrated $8.1 \mathrm{GHz}$ modulation and $22.5 \mathrm{Gbit} / \mathrm{s}$ large signal modulation for InP/InAs QDot lasers. QDash show similar small signal modulation bandwidths, though at significantly higher injection currents and a bit rate of $17.5 \mathrm{Gbit} / \mathrm{s}$ with potential for $20 \mathrm{Gbit} / \mathrm{s}$. Dissipated heat-to-bit rate ratios are as low as 8 and $11 \mathrm{pJ} / \mathrm{bit}$ for QDot and QDash lasers, respectively. Improvement of small- and large-signal operations can be achieved by decreasing the size distribution of dots/dashes ensemble. ${ }^{29}$ Photoluminescence spectra reveal

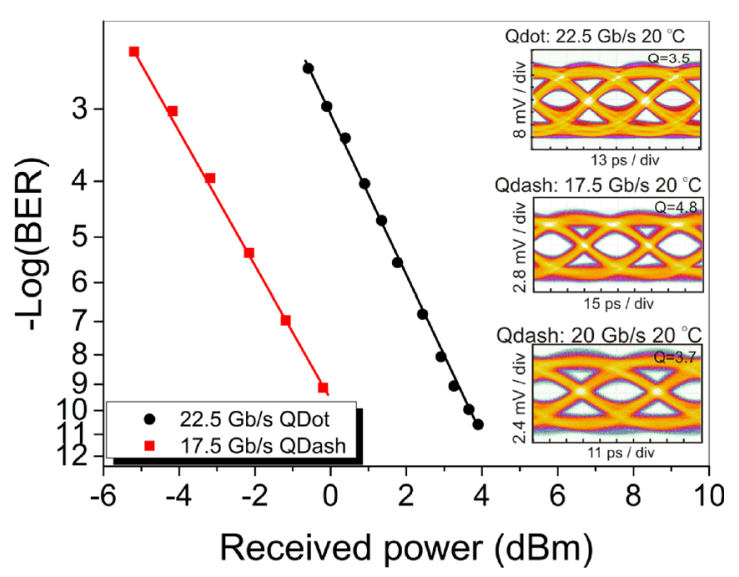

FIG. 4. OOK format bit-error-ratios of QDot/QDash lasers and respective eye diagrams (inset).
FIG. 3. (a) Damping rate vs squared relaxation oscillation frequency; (b) square of resonance frequency (with $-3-\mathrm{dB}$ bandwidths the inset) versus bias. inhomogeneous broadening of 220 and $130 \mathrm{~nm}$ for QDot and QDash ensembles, respectively, ${ }^{30}$ which can be further optimized. It is important to note that parasitic and heating effects can be strongly reduced for the present devices in the future by means of optimized laser chip and mounting leading to further improved dynamic properties of the lasers.

The authors thank D. Franke and J. Kreissl from the Heinrich-Hertz-Institut for material growth and device processing. The authors acknowledge the initial financial support of the Collaborative Research Centre 787 (SFB 787) of the Deutsche Forschungsgemeinschaft and the Seventh Framework Programme through the PROPHET Initial Training Network.

${ }^{1}$ D. Bimberg, "Quantum dot based nanophotonics and nanoelectronics," Electron. Lett. 44(3), 168-171 (2008).

${ }^{2}$ H. Saito, K. Nishi, and S. Sugou, "Ground-state lasing at room temperature in long-wavelength InAs quantum-dot lasers on $\operatorname{InP}(311) \mathrm{B}$ substrates," Appl. Phys. Lett. 78(3), 267-269 (2001).

${ }^{3}$ N. Kirstaedter, N. Ledentsov, M. Grundmann, D. Bimberg, V. Ustinov, S. Ruvimov, M. Maximov, P. Kop'ev, Z. Alferov, U. Richter, P. Werner, U. Gösele, and J. Heydenreich, "Low threshold, large To injection laser emission from (InGa)As quantum dots," Electron. Lett. 30(17), 1416 (1994).

${ }^{4}$ N. Kirstaedter, O. Schmidt, N. Ledentsov, D. Bimberg, V. Ustinov, A. Egorov, A. Zhukov, M. Maximov, P. Kop'ev, and Z. Alferov, "Gain and differential gain of single layer InAs/GaAs quantum dot injection lasers," Appl. Phys. Lett. 69(9), 1226 (1996).

${ }^{5}$ O. Schmidt, N. Kirstaedter, N. Ledentsov, M. Mao, D. Bimberg, V. Ustinov, A. Egorov, A. Zhukov, M. Maximov, P. Kop'ev, and Z. Alferov, "Prevention of gain saturation by multi-layer quantum dot lasers," Electron. Lett. 32(14), 1302 (1996).

${ }^{6}$ R. Schwertberger, D. Gold, J. Reithmaier, and A. Forchel, "Long-wavelength InP-based quantum-dash lasers," IEEE Photonics Technol. Lett. 14(6), 735-737 (2002).

${ }^{7}$ J. Reithmaier, G. Eisenstein, and A. Forchel, "InAs/InP quantum-dash lasers and amplifiers," Proc. IEEE 95(9), 1779-1790 (2007).

${ }^{8}$ D. Gready and G. Eisenstein, "Carrier dynamics and modulation capabilities of $1.55-\mu \mathrm{m}$ quantum-dot lasers," IEEE J. Sel. Top. Quantum Electron. 19(4), 1900307 (2013).

${ }^{9}$ H. Dery and G. Eisenstein, "The impact of energy band diagram and inhomogeneous broadening on the optical differential gain in nanostructure lasers," IEEE J. Quantum Electron. 41(1), 26-35 (2005).

${ }^{10} \mathrm{H}$. Dery and G. Eisenstein, "Self-consistent rate equations of self-assembly quantum wire lasers," IEEE J. Quantum Electron. 40(10), 1398-1409 (2004).

${ }^{11}$ R. Schwertberger, D. Gold, J. Reithmaier, and A. Forchel, "Epitaxial growth of $1.55 \mu \mathrm{m}$ emitting InAs quantum dashes on InP-based heterostructures by GS-MBE for long-wavelength laser applications," J. Cryst. Growth 251(1-4), 248-252 (2003).

${ }^{12} \mathrm{Z}$. Mi and P. Bhattacharya, "DC and dynamic characteristics of P-doped and tunnel injection 1.65- $\mu \mathrm{m}$ InAs quantum-dash lasers grown on InP (001), " IEEE J. Quantum Electron. 42(12), 1224-1232 (2006).

${ }^{13}$ O. Mollet, A. Martinez, K. Merghem, S. Joshi, J.-G. Provost, F. Lelarge, and A. Ramdane, "Dynamic characteristics of undoped and p-doped 
Fabry-Perot InAs/InP quantum dash based ridge waveguide lasers for access/metro networks," Appl. Phys. Lett. 105(14), 141113 (2014).

${ }^{14}$ M. Heck, E. Bente, B. Smalbrugge, Y. Oei, M. Smit, S. Anantathanasarn, and R. Nötzel, "Observation of Q-switching and mode-locking in twosection InAs/InP (100) quantum dot lasers around $1.55 \mu \mathrm{m}$," Opt. Express 15(25), 16292-16301 (2007).

${ }^{15}$ D. Franke, M. Moehrle, J. Boettcher, P. Harde, A. Sigmund, and H. Kuenzel, "Effect of metal organic vapor phase epitaxy growth conditions on emission wavelength stability of $1.55 \mu \mathrm{m}$ quantum dot lasers," Appl. Phys. Lett. 91(8), 081117 (2007).

${ }^{16}$ J. Reithmaier, A. Somers, S. Deubert, R. Schwertberger, W. Kaiser, A. Forchel, M. Calligaro, P. Resneau, O. Parillaud, S. Bansropun, M. Krakowski, R. Alizon, D. Hadass, A. Bilenca, H. Dery, V. Mikhelashvili, G. Eisenstein, M. Gioannini, I. Montrosset, T. Berg, M. Poel, J. Mørk, and B. Tromborg, "InP based lasers and optical amplifiers with wire-/dot-like active regions," J. Phys. D: Appl. Phys. 38(13), 2088 (2005).

${ }^{17}$ P. Borri, W. Langbein, J. Hvam, F. Heinrichsdorff, M. Mao, and D. Bimberg, "Ultrafast gain dynamics in InAs-InGaAs quantum-dot amplifiers," IEEE Photonics Technol. Lett. 12(6), 594-596 (2000).

${ }^{18} \mathrm{P}$. Bhattacharya, "In(Ga)As/GaAs self-organized quantum dot lasers: DC and small-signal modulation properties," IEEE Trans. Electron Devices 46(5), 871-883 (1999).

${ }^{19}$ S. Banyoudeh, A. Abdollahinia, O. Eyal, F. Schnabel, V. Sichkovskyi, G. Eisenstein, and J. Reithmaier, "High-speed directly modulated $1.5-\mu \mathrm{m}$ quantum dot lasers," Proc. SPIE 9767, 97670L (2016).

${ }^{20}$ N. Chimot, S. Joshi, G. Aubin, K. Merghem, S. Barbet, A. Accard, A. Ramdane, and F. Lelarge, " $1550 \mathrm{~nm}$ InAs/InP quantum dash based directly modulated lasers for next generation passive optical network," in International Conference on Indium Phosphide Related Materials (2012), pp. 177-180.

${ }^{21}$ M. Khan, T. Ng, and B. Ooi, "Self-assembled InAs/InP quantum dots and quantum dashes: Material structures and devices," Prog. Quantum Electron. 38(6), 237-313 (2014).
${ }^{22}$ D. Franke, J. Kreissl, W. Rehbein, F. Wenning, H. Kuenzel, U. Pohl, and D. Bimberg, "Effect of the shape of InAs nanostructures on the characteristics of InP-based buried heterostructure semiconductor optical amplifiers," Appl. Phys. Express 4(1), 14101 (2011).

${ }^{23}$ D. Arsenijević, A. Schliwa, H. Schmeckebier, M. Stubenrauch, M. Spiegelberg, D. Bimberg, V. Mikhelashvili, and G. Eisenstein, "Comparison of dynamic properties of ground- and excited-state emission in p-doped InAs/GaAs quantum-dot lasers," Appl. Phys. Lett. 104(18), 181101 (2014).

${ }^{24}$ K. Uomi, T. Tsuchiya, M. Aoki, and N. Chinone, "Oscillation wavelength and laser structure dependence of nonlinear damping effect in semiconductor lasers," Appl. Phys. Lett. 58(7), 675-677 (1991).

${ }^{25}$ P. A. Morton, T. Tanbun-Ek, R. A. Logan, A. M. Sergent, P. F. Sciortino, and D. L. Coblentz, "Frequency response subtraction for simple measurement of intrinsic laser dynamic properties," IEEE Photonics Technol. Lett. 4(2), 133-136 (1992).

${ }^{26}$ F. Grillot, N. Naderi, M. Pochet, C.-Y. Lin, and L. Lester, "Variation of the feedback sensitivity in a $1.55 \mu \mathrm{m}$ InAs/InP quantum-dash Fabry-Perot semiconductor laser," Appl. Phys. Lett. 93(19), 191108 (2008).

${ }^{27}$ C. Chen, Y. Wang, H. S. Djie, B. S. Ooi, L. Lester, T. L. Koch, and J. Hwang, "Intrinsic dynamics of quantum-dash lasers," IEEE J. Sel. Top. Quantum Electron. 17(5), 1167-1174 (2011).

${ }^{28}$ D. Gready, G. Eisenstein, V. Ivanov, C. Gilfert, F. Schnabel, A. Rippien, J. Reithmaier, and C. Bornholdt, "High speed $1.55 \mu \mathrm{m} \mathrm{InAs/InGaAlAs/}$ InP quantum dot lasers," IEEE Photonics Technol. Lett. 26(1), 11-13 (2014).

${ }^{29}$ D. Deppe, S. Freisem, H. Huang, and S. Lipson, "Electron transport due to inhomogeneous broadening and its potential impact on modulation speed in p-doped quantum dot lasers," J. Phys. D: Appl. Phys. 38(13), 2119-2125 (2005).

${ }^{30}$ A. Lenz, F. Genz, H. Eisele, L. Ivanova, R. Timm, D. Franke, H. Künzel, U. W. Pohl, and M. Dähne, "Formation of InAs/InGaAsP quantum-dashes on InP(001)," Appl. Phys. Lett. 95(20), 203105 (2009). 